Bond University

Research Repository

\title{
Amino Acid Kinetics and the Response to Nutrition in Patients with Cancer
}

van der Meij, Barbara S; Teleni, Laisa; Engelen, Marielle Pkj; Deutz, Nicolaas Ep

Published in:

International Journal of Radiation Biology

DOI:

10.1080/09553002.2018.1466209

Licence:

Unspecified

Link to output in Bond University research repository.

Recommended citation(APA):

van der Meij, B. S., Teleni, L., Engelen, M. P., \& Deutz, N. E. (2019). Amino Acid Kinetics and the Response to Nutrition in Patients with Cancer. International Journal of Radiation Biology, 95(4), 480-492.

https://doi.org/10.1080/09553002.2018.1466209

\section{General rights}

Copyright and moral rights for the publications made accessible in the public portal are retained by the authors and/or other copyright owners and it is a condition of accessing publications that users recognise and abide by the legal requirements associated with these rights.

For more information, or if you believe that this document breaches copyright, please contact the Bond University research repository coordinator. 


\section{Amino Acid Kinetics and the Response to Nutrition in Patients with Cancer}

Barbara S van der Meij ${ }^{1,2}$, Laisa Teleni ${ }^{1}$, Marielle PKJ Engelen ${ }^{3}$, Nicolaas EP Deutz ${ }^{3}$

1. Faculty of Health Sciences and Medicine, Bond University, Gold Coast, Australia

2. Nutrition and Dietetics, Mater Group, Brisbane, Australia

3. Center for Translational Research in Aging \& Longevity.' Dept. Health and Kinesiology, Texas A\&M University, College Station, TX, USARE

\section{Barbara S van der Meij - corresponding author (BM)}

Mater Group

Salmon Building, Raymond Terrace

South Brisbane QLD 4101

Australia

Email: barbara.vandermeij@mater.org.au

Phone: +61-413 835739

Orcid ID: 0000-0002-0412-2801

LinkedIn: https://www.linkedin.com/in/barbara-van-der-meij-6478b1b/

\section{Laisa Teleni (LT)}

Bond Institute of Health and Sport

2 Promethean Way

Gold Coast QLD 4226

Australia

Email: laisa.teleni@student.bond.edu.au

Phone: +61-420 528857

Orcid ID: 0000-0001-9321-9586

LinkedIn: www.linkedin.com/in/laisateleni

\section{Marielle PKJ Engelen (ME)}

Texas A\&M University 
Department of Health and Kinesiology

Center for Translational Research in Aging and Longevity

675 John Kimbrough Boulevard

TAMU 4253

College Station TX 77843-4253

United States of America

Phone: +1-979 4221789

Email: mpkj.engelen@ctral.org

LinkedIn: https://www.linkedin.com/in/marielle-engelen-b5880a32/

Orcid ID: 0000-0001-9884-2553

Nicolaas EP Deutz (NP)

Texas A\&M University

Department of Health and Kinesiology

Center for Translational Research in Aging and Longevity

675 John Kimbrough Boulevard

TAMU 4253

College Station TX 77843-4253

United States of America

Phone: +1-979 4221789

Email: nep.deutz@ctral.org

LinkedIn: https://www.linkedin.com/in/nicolaas-deutz-801794122/

Orcid ID: 0000-0001-5845-6447

\section{Keywords:}

Amino acids, anabolic response, protein metabolism

Word Count (excluding abstract, references, figure and tables):

6047 


\section{Abstract}

\section{Purpose}

Amino acids are involved in many physiological processes in the body and serve as building blocks of proteins which are the main component of muscle mass. Often patients with cancer experience muscle wasting, which is associated with poor outcomes. The purpose of this paper is to discuss amino acid kinetics in cancer, review the evidence on the response to nutrition in patients with cancer, and to give recommendations on the appropriate level of amino acid or protein intake in cancer.

Current evidence shows that amino acid kinetics in patients with cancer are disturbed, as reflected by increased and decreased levels of plasma amino acids, an increased whole body turnover of protein and muscle protein breakdown. A few studies show beneficial effects of acute and short-term supplementation of high protein meals or essential amino acid mixtures on muscle protein synthesis.

\section{Conclusion}

Cancer is associated with disturbances in amino acid kinetics. A high protein intake or supplementation of amino acids may improve muscle protein synthesis. Future research needs to identify the optimal level and amino acid mixtures for patients with cancer, in particular for those who are malnourished. 


\section{Introduction}

Amino acids are the building blocks of proteins and polypeptides and regulate key metabolic pathways that are necessary for maintenance, growth, reproduction, and immunity. They are key precursors for hormone synthesis and other nitrogenous substances involved in body functions. As such, maintaining physiological concentrations of amino acids and their metabolites (e.g. nitric oxide or serotonin) are essential and in contrast cases elevated levels of amino acids and related products (e.g. ammonia or homocysteine) can be harmful and cause neurological disorders, oxidative stress and cardiovascular disease (Deutz et al. 2017). For homeostasis, the body requires an optimal balance of amino acids in the diet and the circulation (Wu 2009).

The growth of cancer leads to alterations in the host's metabolism. For example, proinflammatory cytokines produced by or in response to the tumor stimulate the synthesis of acute phase protein reactants and can interact the neuroendocrine axis resulting in anorexia and increased energy expenditure, increasing the requirements for protein and energy. Under these circumstances, there is an ongoing, progressive, breakdown of muscle mass and fat tissue (Khalid et al. 2007; Engelen M.P. et al. 2016; Argilés 2017). However, there is a variability in energy demands in cancer with some patients showing to be hypometabolic (REF Lelbach 2007). In these instances, there is evidence to suggest that patients compensate with reduced physical activity levels (REF Moses 2004). Despite metabolic alterations, a few studies have demonstrated that patients with cancer can reach muscle protein anabolism with oral or parenteral amino acid nutrition supplements or protein-rich meals (Deutz et al. 2011; Peters et

al. 2011; van Dijk et al. 2015; Engelen M. P. et al. 2016). However, tumor-induced anorexia and 
physiological changes associated with the tumor, such as obstruction and dysphagia and potential malabsorption and maldigestion often diminish food intake (Argilés 2017). This can be exacerbated by anti-cancer treatment-related side effects such as nausea, vomiting and dysgeusia (Sánchez-Lara et al. 2010; Hébuterne et al. 2014; Arends et al. 2017).

Weight loss (DeWys et al. 1981; Prado et al. 2013; Hébuterne et al. 2014; Martin et al. 2014) and malnutrition are prevalent in patients with cancer. Recent studies have shown that up to $50 \%$ of patients with cancer are malnourished or at risk of malnutrition based on their degree of involuntary weight loss (usually more than $5 \%$ in 1 month, or more than $10 \%$ in 6 months) (Hébuterne et al. 2014; Gioulbasanis et al. 2015).

The progressive loss of skeletal muscle mass and strength or physical function is known as sarcopenia (REF Cruz-Jentof, 2010). When seen in patients with a high percentage of body fat, it is called 'sarcopenic obesity' (Carneiro et al. 2016). On average, 39\% (11-74\%) of patients with cancer experience muscle wasting or sarcopenia (Pamoukdjian et al. 2017) depending on the stage and type of cancer (Shachar et al. 2016).

Cancer cachexia is also a syndrome of progressive weight loss and muscle wasting that is also characterized by anorexia, inflammation, insulin resistance and muscle protein breakdown (Fearon K et al. 2011; Cederholm et al. 2017). By definition, the muscle loss in cancer cachexia cannot be fully reversed by conventional nutrition support (i.e. provision of oral, enteral or parenteral nutrition to maintain or restore optimal nutrition status and health (REF ASPEN:

http://www.nutritioncare.org/About Clinical Nutrition/What is Nutrition Support Therapy/)

(Fearon K et al. 2011). This is due to the complexity of the cancer cachexia syndrome and the 
suspected anabolic resistance, in particular in advanced disease ('refractory cachexia') (REF Fearon 2011).

Both the amount and the quality of muscle in the body are relevant to patients with cancer. A low muscle mass is associated with a poorer quality of life (Hung et al. 2013), postoperative complications (Härter et al. 2017; Rutten et al. 2017), higher treatment toxicity and shorter survival (Deans et al. 2009; Prado et al. 2013; Martin et al. 2014; Tanaka et al. 2017). Sarcopenia is associated with muscle weakness (Cruz-Jentoft et al. 2010; Biolo Gianni et al. 2014; Naito et al. 2017). Several studies show that patients with cancer experience muscle weakness in those undergoing chemotherapy (Gilliam and St Clair 2011; Vermaete et al. 2014; Midgley et al. 2017; Teodozio et al. 2017), stem cell transplant (Tanaka et al. 2017) and even those without active treatment (Norman Kristina et al. 2010; Vermaete et al. 2014; Owusu et al. 2017). Muscle quality refers to the amount of contractile vs. non-contractile muscle and muscle composition, including the amount of intramuscular fat droplets (reflected by muscle attenuation on CT scans). Skeletal muscle attenuation is associated with increased postoperative complications and shorter survival (Sjøblom et al. 2016; Silva de Paula et al. 2018).

Certain chemotherapy regimens and hormonal alterations affect protein and fat metabolism and food intake (Argilés et al. 2015). This often results in weight gain and fat deposition in so-called 'adiposity-related cancers', such as breast, endometrial and prostate cancer (Allott and Hursting 2015; Keum et al. 2015; van den Berg et al. 2017). This side effect of cancer treatment is also problematic, as obesity or a high percentage of body fat are associated with shorter survival (Martin et al. 2013). 
To develop and test interventions targeting muscle wasting in cancer, we need to understand the metabolic processes behind muscle wasting. The aim of this review is to discuss amino acid kinetics in cancer and the response to nutrition in patients with cancer. We will provide recommendations about the optimal intake of amino acids for patients with cancer and discuss areas for future research. 


\section{Changes in plasma and muscle amino acids in cancer}

\section{Disturbances in amino acid metabolism}

Amino acids are basic metabolites and metabolic regulators that circulate in the plasma for transport to peripheral tissues (Lai et al. 2005). In the presence of a tumor the demand for amino acids increases and there is a corresponding increase in protein turnover (i.e., the balance between muscle protein synthesis and breakdown) (Jeevanandam et al. 1984). This is exacerbated by inflammation as there is an increased proportion of splanchnic amino acids that are extracted to support the hepatic synthesis of acute phase protein response reactants (Jonker et al. 2012). There is preferential consumption of certain amino acids, in particular essential amino acids (EAAs) (Proenza et al. 2003; Jonker et al. 2012). In terms of non-essential amino acids (NEAAs) there is a demand for glutamine, glycine and aspartate to support tumor growth and serine for membrane lipid component synthesis.

Skeletal muscle is a reservoir of amino acids, glucose and intramuscular lipids that can support protein synthesis or energy production elsewhere in the body, for instance for the formation of glucose or glycogen (Perriello et al. 1997; Brook et al. 2017). In cancer, the homeostatic regulation of protein turnover is disturbed. The increased demands for energy can upregulate muscle protein breakdown to provide amino acid substrates for glucose and glycogen formation, causing protein depletion and loss of skeletal muscle mass (Brook et al. 2017). Further, muscle protein synthesis is diminished (as discussed later) and increased muscle apoptosis contributes to a negative muscle protein balance (Argilés 2017).

Energy balance can be altered by decreased food intake and hypermetabolism. One of the factors of hypermetabolism is mitochondrial dysfunction, which causes decreased ATP 
synthesis and oxidative phosphorylation uncoupling and reduces energy efficiency (Argilés 2017). Triggered by inflammatory mediators, white adipose cells are converted into brown adipose cells, which promote heat production and energetic inefficiency (Argilés 2017). The severity of metabolic disorders in cancer depends on the extent of the host response, which is dependent on the stage and type of the cancer (Fearon K et al. 2011). The following paragraphs give an overview of studies investigating alterations in plasma and muscle amino acids in patients with cancer.

\section{Plasma amino acid concentrations}

Profiles of plasma free amino acids in cancer can be influenced by several factors, one of them being dietary intake. When protein from the diet is digested and absorbed by the gut, amino acids are extracted by the splanchnic area or released into the systemic circulation. In this way, dietary protein intake and starvation impact on plasma amino acid concentrations (Jonker B J Nutr2012, S139-S148). Further, disease, inflammation and anti-cancer treatments may alter the absorption, digestion or utilization of amino acids resulting in enhanced endogenous protein breakdown consequently altering plasma amino acid profiles. In cancer this could be more profound because of the metabolic demands of the tumour, requiring amino acids for protein synthesis and tumour growth (Jonker B J Nutr2012, S139-S148, then Have 2007 S23-S36).

Several studies investigated plasma amino acid profiles (Table 1) and documented significant differences between patients with cancer and healthy subjects. Few studies have investigated differences between early and late stage cancers, and some explored these profiles in patients with anorexia and weight loss. This section discusses studies investigating 
plasma amino acid concentrations in cancer that have been published in the last 15 years (Vissers et al. 2005; Miyagi et al. 2011; Shen et al. 2013; Ihata et al. 2014; Ma et al. 2014; Fukutake et al. 2015). .

Lai et al. (2005) reviewed 13 clinical studies in patients with heterogeneous cancer types. Lai proposed that patients with cancer exhibited a specific 'cancer-related' amino acid profile, of reduced levels of plasma alanine, arginine, aspartate, citrulline, cysteine, glutamine, glycine, histidine, isoleucine, leucine, lysine, methionine, phenylalanine, proline, serine, taurine, threonine, tryptophan, tyrosine and valine, and elevated levels of plasma ornithine. More specifically, Lai et al. (2005) found that plasma amino acids were frequently elevated in breast cancer (specifically alanine, arginine, proline and tryptophan). Similarly, Miyagi et al. (2011) found increased levels of amino acids in patients with breast cancer. In contrast to Lai et al. (2005) and Miyagi et al. (2011), our investigation of the metabolism of arginine and the interrelated amino acids glutamine and citrulline in cancer (see Figure 1) revealed lower plasma arginine, citrulline and glutamine concentrations in pre-surgical patients with early stage breast cancer compared with healthy controls (Engelen M.P. et al. 2016). Further we found that weight-stable patients with T1 to T3 breast cancer had decreased plasma arginine (not glutamine or citrulline) and other amino acids such as tryptophan and arginine (Vissers et al. 2005). This was especially visible in those with ripple-negative breast cancer. Thus, findings in patients with breast cancer are inconclusive, which could be explained by differences between individual studies in the type and stage of breast cancer and the type of treatment (e.g. surgery vs. palliative care). 
Further to the findings in breast cancer, Lai et al. (2005) found that plasma amino acids were frequently depressed in digestive organ cancers, but there were no discernable trends in other cancers. Miyagi et al. (2011) also found decreased levels in patients with gastric and colorectal cancers. Our group showed similar results where plasma levels of arginine were decreased in patients with colonic (Vissers et al. 2005), pancreatic (Vissers et al. 2005) as well as lung (Engelen M.P. et al. 2016) cancer. In gynecological cancers, plasma amino acids have been investigated as potential biomarkers for diagnosis and monitoring of disease. Turkoglu et al. (2016) systematically reviewed metabolomics studies in human ovarian cancer and concluded that plasma concentrations of glutamine, glutamate, cysteine, glycine and threonine were increased and L-tryptophan and phenylalanine were decreased in ovarian cancer. Plasma valine and alanine could be either increased or decreased (Turkoglu et al. 2016). In endometrial cancer, plasma valine, tryptophan and phenylalanine were decreased in patients with cancer compared to age- and BMI-matched control subjects (Ihata et al. 2014).

Importantly, advanced disease and malnutrition were associated with more profound changes in plasma amino acids in some studies, as indicated by Lai et al. (2005). It has been suggested that increased muscle protein breakdown provides substrates for enhanced gluconeogenesis in the liver and enhanced branched chain amino acid (BCAA) oxidation in muscle. This would result in normal or higher BCAA levels in early-stage cancer. In late-stage cancer, muscle protein breakdown can cease as the tumor progresses, as reflected by lower levels of BCAA and EAA (Lai et al. 2005; Turkoglu et al. 2016). This hypothesis is in contrast with Miyagi et al. (2011) findings that changes in plasma amino acids are independent of malnutrition or tumor progression. Miyagi reported decreased concentrations in plasma amino 
acids profiles in patients with both early and late stage disease, where patients with early stage disease did not have significant weight loss, anorexia or serum albumin depletion.

In order to assess cancer cachexia risk by examining amino acid concentration and analyzing amino acid balance, Kitagawa et al. (2017) conducted a retrospective chart review of consecutive patients with unresectable advanced gastrointestinal cancer (stage IV) receiving chemotherapy treatment. Results showed that an increase in psoas (hip flexor) muscle index over time was related to a lower EAA/total amino acid (TAA) ratio. Serum C-reactive protein (CRP), leucine, and isoleucine were negatively correlated with increases in muscle index and there was a strong negative correlation between serum CRP and change in muscle index. This suggests that when EAAs are used for muscle build up plasma EAA/TAA ratios decline, whereas skeletal muscle protein breakdown was associated with higher plasma EAA/TAA ratios.

In conclusion, many studies have shown that patients with cancer have altered levels of plasma amino acids. Alterations in plasma amino acids can be present in early-stage patients who are in a good nutritional status. There is conflicting evidence whether plasma amino acid variations are more profound in patients with metabolic alterations, metastatic cancer, anorexia, weight loss and/or malnutrition. Although most studies investigated fasted plasma samples, this was unclear for a few studies, complicating the interpretation and collation of results. Also, more controlled research is needed to clarify the value of using plasma amino acid profiles to be used as a marker for cancer screening and diagnosis.

Cancer, muscle wasting, sarcopenia and cachexia can alter the plasma profile of amino acids, but whether there is a resultant change in the amino acid profile of muscle tissue is less clear. Muscle serves as a major reservoir of amino acids, containing approximately half of the 
body's free amino acid pool (de Blaauw et al. 1997). Evaluating muscle amino acids requires invasive techniques such as muscle biopsy. Therefore, in patients with cancer, whole body protein turnover is often evaluated using radioactive or, more commonly, stable isotope techniques.

In a recent review by Engelen MPKJ et al. (2016), it was noted that the rate of whole body protein turnover was highly variable across patients with cancer and likely influenced by the presence and magnitude of inflammation associated with cancer. For example, in a study of11 mostly malnourished patients with colorectal cancer, Carmichael et al. (1980) showed whole body protein turnover was significantly higher in patients with cancer than in non-cancer controls. In these patients, the rate of protein synthesis and breakdown increased with the advancement of cancer, but was significantly lower in patients with anorexia. When compared with weight-stable controls, van Dijk et al. (2015) found that patients with pancreatic cancer had higher whole body protein turnover where protein breakdown was associated with CRP. Both the rate of protein breakdown and synthesis were significantly higher in weight-losing patients versus weight-stable non-cancer controls. The rate of protein synthesis in the cancer group did not respond to sip feeds, but the rate of protein breakdown decreased enabling patients to reach a positive protein balance. Similarly, Williams et al. (2012) showed that preoperative fasted muscle protein synthesis rates of colon cancer patients were comparable to those of healthy controls. However, unlike healthy controls, there was no muscle synthetic response to feeding. There was a trend for increases under fed and fasted conditions in preoperative muscle protein breakdown compared with healthy controls, but this was not 
statistically significant. However, after the surgical removal of the cancer, both synthesis and breakdown normalized to the rates demonstrated by healthy controls.

Fearon KC et al. (1988) showed that patients with lung and colon cancer had significantly higher rates of whole body protein turnoverand breakdown but comparable rates of synthesis compared with non-cancer controls. When analyzed by weight status, there were no differences between weight-losing ( $>5 \%$ weight loss) and weight-stable patients with cancer.In contrast, MacDonald et al. (2015) found that myofibrillar protein breakdown was comparable, but there were significantly higher protein synthetic rates in weight-losing versus weight stable patients with early stage gastric cancer, In

In Dworzak et al. (1998) found the rate of whole body protein turnover was comparable between patients with advanced gastric cancer and healthy controls. When evaluated across the forearm muscle, the rate of muscle protein synthesis was significantly lower in the cancer group. These studies suggest that differences in whole body protein turnover are likely associated with inflammation, nutritional status, tumor presence and cancer stage. Anabolic stimuli in cancer

\section{Dietary protein}

Many factors contribute to the activation of protein breakdown in cancer. The expression of proteolysis-inducing factor (PIF) by tumors induces enhanced protein breakdown(Argilés 2017). The ubiquitin-proteasome and autophagic-lysosomal pathways are upregulated exacerbating skeletal muscle protein breakdown. There are changes in the rate of myogenesis and apoptosis, decreasing the regenerative capacity of skeletal muscle and 
increasing the rate of cell death. Other factors include inflammatory cytokines, the activation of NF-kappa B and the suppression of mTOR activity.

As a result of the enhanced inflammatory response and protein breakdown, there is an increased need for dietary protein in cancer (Guadagni and Biolo 2009). However, often patients with cancer have a reduced nutritional intake as a consequence of anorexia and symptoms related to the tumor or caused by cancer treatments (Sánchez-Lara et al. 2010; Coa et al. 2015). A few studies investigated the relation between protein intake and clinical outcomes in patients with cancer. Stobaus et al. (2015) showed that in 285 patients with mixed types of cancer undergoing chemotherapy, $66 \%$ had a low protein intake $(<1 \mathrm{~g} / \mathrm{kg}$ body weight)(REF Arends 2017), and a low protein intake was associated with a more than twofold higher risk of cancer-related fatigue and 6-month mortality. In a smaller study in 41 patients with breast cancer undergoing chemotherapy, dietary intake was not correlated with healthrelated quality of life (Lua et al. 2012). In a study in 50 patients with cancer admitted to the hospital, $33 \%$ of all patients did not reach daily energy requirements of $25 \mathrm{kcal} / \mathrm{kg}$ and $23 \%$ had a dietary protein intake of less than $1 \mathrm{~g}$ protein $/ \mathrm{kg} /$ day. A protein intake of $<1 \mathrm{~g} / \mathrm{kg} /$ day was associated to a poorer self-reported physical functioning and fatigue. No significant differences were found regarding caloric intake and QoL (Trabal et al. 2006). Bosaeus et al. (2002) investigated dietary intake, energy metabolism and weight loss in 297 patients with generalized malignant disease undergoing palliative care involving anti-inflammatory treatment and nutritional counselling during 4 months. At enrollment, dietary energy and protein intake were low. Energy intake slightly increased during the intervention period and a higher dietary energy intake predicted longer survival. There was no correlation between protein intake and survival. 
A study in outpatients with mixed types of cancer who were at high risk of malnutrition or malnourished showed that individual nutritional therapy provided by a dietitian vs. standard care for 3 months improved daily energy and protein intake $(+379 \mathrm{kcal}$ and $+10 . \mathrm{g}$ protein, respectively, $\mathrm{P}<0.05)$, but this was not associated with improvements in nutritional status, physical functioning, or quality of life (Uster et al. 2013). In a RCT in head and neck cancer, patients who received dietary counseling had a higher energy and protein intake during radiotherapy compared to patients receiving only supplements or usual care $(+521 \mathrm{kcal}$ vs. $+322 \mathrm{kcal}$ and $-400 \mathrm{kcal}$, and $+26 \mathrm{~g},+35 \mathrm{~g},-15 \mathrm{gd}$ protein, respectively, $\mathrm{P}<0.01)$. They also reported a better QoL and a reduced incidence or severity of RT toxicity symptoms after 3 months (Ravasco et al. 2005). Baldwin et al systematically reviewed effects of oral nutritional interventions for patients with cancer, and showed that these are effective at increasing energy intake with $432 \mathrm{kcal} / \mathrm{d}$ and improving some aspects of quality of life (Baldwin et al. 2012). In conclusion, nutritional counseling and oral nutritional interventions in patients with cancer improve dietary intake and quality of life, however body composition and survival were not investigated in these studies.

We only identified two studies on the relationship between dietary intake and muscle mass in patients with cancer. There are a few, small studies investigating the short-term effect of protein and amino acid-enriched nutrition supplements on muscle anabolism in patients with cancer. Although some amino acid-enriched nutrition supplements (e.g., BCAAs) appear to overcome the anabolic resistance of muscle in cancer, it is less clear whether the anabolic effects would be sustained with longer-term supplementation and what the overall effects on muscle quantity, quality and function would be. Studies on supplementation of glutamine in 
catabolic conditions looking at effects on chemotherapy toxicity show inconsistent results.

There are currently no guidelines with regards to the minimal threshold of protein per meal or mid-meal, and the optimal number and frequency of high-protein meals throughout the day.

In conclusion, dietary protein intake is often suboptimal in patients with cancer. Some studies found an association between protein intake levels, either or not established by nutritional therapy or supplements, and quality of life and survival, but more research is needed to confirm this.

\section{What is the optimal amount of amino acids/protein in patients with cancer?}

The most recent evidence-based dietary guidelines for patients with cancer, published by the European Society for Clinical Nutrition and Metabolism(ESPEN), recommend a protein intake of at least $1 \mathrm{~g}$ per kg body weight per day, if possible up to $1.5 \mathrm{~g} / \mathrm{kg} / \mathrm{day}$ (Arends et al. 2017). Expert opinions suggest the optimal range of dietary protein for patients with cancer to be $1.0-2.0 \mathrm{~g} / \mathrm{kg} / \mathrm{day}$. This is based on existing acute studies focused on metabolic endpoints and benefits, not on long-term studies showing benefits on muscle maintenance. These studies showed that an elevated protein intake promoted muscle protein anabolism in patients with cancer (Winter et al. 2012; Baracos 2015; MacDonald et al. 2015). A critical literature appraisal by Bozzetti (2013) concluded that the dose of amino acids capable of supporting a positive protein balance in patients with cancer might be close to $2 \mathrm{~g} / \mathrm{kg} / \mathrm{d}$. The ESPEN committee also stated that protein in doses up to and above $2 \mathrm{~g} / \mathrm{kg} / \mathrm{d}$ are safe; in patients with acute or chronic renal failure protein supply should not exceed 1.0 or $1.2 \mathrm{~g} / \mathrm{kg} / \mathrm{d}$, respectively (Arends et al. 2017). The clinical guidelines of the American Society of Parenteral and Enteral Nutrition 
(ASPEN) for nutrition support during adult anticancer treatment do not provide specific guidelines for amino acids or protein (August and Huhmann 2009).

There is concern that estimating equations based on body weight would fail to account for the variability in body composition (Geisler et al. 2016). This concern is particularly relevant in cancer where sarcopenia, especially sarcopenic obesity and cancer cachexia are prevalent. Current recommendations of $1 \mathrm{~g} / \mathrm{kg}$ body weight/day might under- or over- estimate protein requirements for lean mass.

This concept was explored by Geisler et al. (2016) in a recent theoretical exercise where protein requirements were estimated based on lean mass instead of body weight. Geisler et al. (2016) calculated lean mass (CT at the L3 landmark), and assumed a dietary protein intake of $0.8 \mathrm{~g} / \mathrm{kg} \mathrm{BW} /$ day for 547 patients with stage III/IV non-small cell lung cancer. Under these assumptions, $97.4 \%$ of patients would present with low protein intake per $\mathrm{kg}$ of lean mass. Although this exercise was based on multiple assumptions (for example, assumed dietary protein intake based on data from healthy subjects), the variation in lean mass of patients with cancer indicates that further study is required. Protein quality is the extent to which the amino acids of a certain protein match the amino acid needs of the consumer, and the efficiency with which the amino acids are extracted from the diet and uses them for growth or maintenance purposes (Marinangeli and House 2017). In 2012, the FAO suggested to express protein quality as the 'digestible indispensable amino acid score' or DIAAS which takes into account the content, pattern and bioavailability (including digestibility) of EAAs (Marinangeli and House 2017). Protein quality differs between dietary sources, and therefore the FAO recommends a consumption of a significant amount of high-quality proteins on a daily basis for all healthy 
subjects. Table 2 displays the DIAAS for common protein-rich foods and shows that in general, animal-based foods have a higher DIAAS than plant-based foods. The ESPEN guidelines (Arends et al. 2017) also recommend good quality protein from animal, fish, dairy and plant sources for the majority of patients with cancer requiring nutrition support for a short period of time. Increasing dietary protein intake should satisfy any increase in protein demand thereby preventing muscle wasting. There has been little success of nutrition interventions in reversing or preventing muscle wasting suggesting muscle protein anabolic resistance.

When excluding studies that investigate the effects of high-protein supplements or sip feeds, two studies have investigated the relation between dietary protein intake and muscle mass in patients with head and neck cancer. In 69 patients, BIA was used to assess body composition before, during and at the end of radiotherapy or chemoradiation. All patients received nutritional counselling, with the majority (95\%) receiving ONS. A dietary intake of $\geq 75 \%$ of the recommended energy and protein intake was considered as compliant $(n=18)$. They found that compliant patients maintained weight and fat free mass over time, whereas in noncompliant patients these decreased significantly. A limitation of this study was that mucositis was less common in compliant patients than in noncompliant patients $(11.1 \%$ versus 88.9\%, resp.) (Hopanci Bicakli et al. 2017). Pistoia et al. (2012) investigated food intake in 62 patients with head and neck cancer undergoing radiotherapy. In three weeks, dietary energy intake reduced from 26.5 to $21.3 \mathrm{kcal} / \mathrm{g} / \mathrm{d}$ and protein intake from 1.19 to $0.93 \mathrm{~g} / \mathrm{kg} / \mathrm{d}$ and there were significant reductions in arm muscle area and arm muscle circumference.

In addition to the studies on dietary protein intake in relation to clinical outcomes which will be discussed in the next paragraph, studies investigating the anabolic potential of muscle 
generally employ stable isotope techniques that enable the calculation of muscle protein synthesis and breakdown rate in response to feeding. For example, Emery et al. (1984) study of 5 weight-losing men with cancer, anorexia and reduced dietary intake vs healthy controls showed that the rate of muscle protein synthesis in the fed state was significantly lower than in the healthy controls. Similarly, Williams et al. (2012) found that although muscle protein breakdown was comparable between preoperative patients with colon cancer and non-cancer controls, the increases in muscle protein synthesis in response to feeding were not evident in the patients with cancer. Conversely, there is some clinical evidence that patients with cancer do have a muscle protein anabolic potential. In a study of 3 month body composition analysis, Prado et al. (2013).showed that in 368 advanced patients with cancer, 45\% maintained and 15\% gained muscle mass. Medical chart review demonstrated that this was likely due to periods of stable disease, symptom control as well as a patient's ability to eat and function.

In summary, patients with cancer experience a disturbed amino acid metabolism, upregulated catabolic processes (enhanced ubiquitin mRNA levels and proteasome activity) in skeletal muscle and hepatic acute phase response. The current guidelines regarding the use of dietary amino acids and protein are unlikely to satisfy the aims of nutrition therapy, mitigate metabolic derangements and maintain skeletal muscle mass.

\section{The effect of amino acids supplementation on metabolism and clinical outcomes}

It is possible that muscle protein synthesis cannot be stimulated with conventional nutrition support in patients with cancer who exhibit muscle wasting, sarcopenia and/or cachexia. For example, although van Dijk et al. (2015) found that a commercially available 
supplement stimulated an anabolic response comparable to that of non-cancer controls, this was only achieved through the reduction of protein breakdown as there was no corresponding response in protein synthesis.

There is still potential for specialized nutrition interventions that target anabolic pathways and provide the substrates for muscle protein synthesis. These may include EAA mixtures or high quality proteins, potentially combined with immune-modulating nutrients such as omega-3 polyunsaturated fatty acids. This idea was explored in Engelen MPKJ et al. (2016) review of whole body protein turnover studies who state it is possible to at least partly overcome anabolic resistance through the provision of high quality proteins. Amino acids are the principal nutrient responsible for stimulating muscle protein synthesis (Wolfe 2002). However, when supplementing with amino acids to simulate synthesis a number of factors should be considered. Firstly, only EAAs are required to stimulate muscle protein synthesis. Tipton et al. (1999) and Wolfe (2002) both showed that NEAAs confer no additional benefit over providing the same amount of EAAs alone. Secondly, it appears that the increasing plasma concentration of EAAs in response to supplementation trigger synthesis, irrespective of the absolute plasma concentration (Wolfe 2002). Thirdly it is possible that there is a limit to the extent to which synthesis can be stimulated during constant intake, with doses of amino acids exceeding $20 \mathrm{~g}$ already exceeding the maximal effective dose in healthy volunteers (Wolfe 2002). Conversely, Engelen MPKJ et al. (2016) showed a linear relationship between dietary EAA availability and net protein gain existed in weight-stable patients with non-small cell lung cancer and weight-losing patients with pancreatic cancer that was comparable to healthy 
controls. This model suggests that higher amounts of EAAs might be useful to patients with cancer.

\section{Branched Chain Amino Acids (BCAA)}

Arguably the most important amino acids are the BCAAs; a subset of EAAs comprised of leucine, isoleucine and valine. Not only are they substrates for muscle protein synthesis and energy metabolism, but leucine is also a key regulator of protein synthesis and breakdown. Under normal conditions, the oxidation of BCAA provides up to $7 \%$ of energy, but in highly catabolic states this can be as high as $20 \%$ (Choudry et al. 2006). The ESPEN guidelines state that there is some evidence that parenteral nutrition containing BCAA result in an improved protein accretion and albumin synthesis when compared to a standard amino acid solution. A number of trials in patients with cancer comparing varying proportions (e.g., $25 \%$ vs $45 \%$ of protein) of BCAA-enriched parenteral nutrition in surgical patients with cancer have been reviewed (Choudry et al. 2006). Although early studies showed some potential benefits of BCAA provision, results from all clinical trials were generally inconsistent in terms of effect on indicators of muscle wasting, muscle amino acid uptake, morbidity and mortality (Choudry et al. 2006).

Dioguardi (2011) proposed an alternative nutrition formula of more than $80 \%$ EAAs (predominantly BCAAs). The NEAA tyrosine was included as it is only non-essential for the liver and the NEAA cysteine was included to prevent methionine from transforming into homocysteine (a toxic intermediate in the methionine to cysteine pathway (Figure 2). This BCAA-enriched formulation has been trialed in few small studies to date reporting improvements in lean muscle mass of sarcopenic elderly subjects (Solerte et al. 2008) and 
weight, albumin and total protein in hemodialysis patients (Bolasco et al. 2011). The most relevant study to cancer was a single-arm, uncontrolled trial conducted in 25 cachectic patients with advanced cancer. After 8 weeks of supplementation, patients had no significant change in weight, BMI, lean body mass (via BIA) or fatigue. There were significant improvements in hand grip strength, albumin and significant reduction in reactive oxygen species (Madeddu et al. 2010). The limitations of this study were its small sample size, lack of control group and heterogeneous mix of patients with cancer in relation to tumor type. Further research is needed to investigate long-term effects of supplementation with body composition analysis sensitive to small changes in muscle mass (e.g., CT).

Leucine and B-hydroxy-6-methylbutyrate (HMB)

One of the most potent activators of muscle protein synthesis is the BCAA leucine. The dose-response effect of leucine on muscle protein synthesis has been demonstrated in mouse cancer cachexia models where a leucine-enriched diet resulted in greater maintenance of lean muscle mass compared with those on a standard diet (Peters et al. 2011). Administration of amino acids as an oral nutrition supplement enriched in leucine and n-3 fatty acids in humans can increase muscle protein synthesis compared to a conventional supplement (Arends et al. 2017). For example, Deutz et al. (2011) demonstrated in a study where a leucine-enriched high protein medical food ( $27 \%$ calories as protein including $4.16 \mathrm{~g}$ free leucine) increased muscle protein synthesis rate by $40 \%$ after 5 hours. Consistent with previous studies, the conventional medical food did not elicit a change in the rate of muscle protein synthesis.

About $0.1 \%$ of leucine is converted into B-hydroxy- $\beta$-methylbutyrate (HMB) (Engelen and Deutz 2018). Although HMB has been shown to reduce skeletal muscle protein breakdown 
and inflammation as well as stimulate muscle protein synthesis, studies in cancer are limited. In an RCT of 32 weight-losing patients with cancer, a daily dose of $3 \mathrm{~g} \mathrm{HMB} / 14 \mathrm{~g}$ arginine/14g glutamine supplement versus an isonitrogenous mix of NEAAs resulted in a $1 \mathrm{~kg}$ gain in fat-free mass in the supplement group (May et al. 2002). One of the larger trials of $\mathrm{HMB} /$ Arginine/Glutamine was conducted in 472 weight-losing patients with advanced cancer. Unfortunately, although there was a trend towards higher lean mass, statistical significance was not reached, possibly due to insufficient data with only $37 \%$ of participants completing the protocol (Berk et al. 2008).

\section{Glutamine}

BCAAs serve as precursors for alanine and glutamine synthesis (Figure $\mathbf{3}$ ) and much of their beneficial effects during catabolism are likely related to the subsequent synthesis of glutamine and blunted release of glutamine from skeletal muscle (Choudry et al. 2006). Glutamine is a key factor in maintaining cellular and vital organ function and modulating immune cell activity (Nicastro et al. 2012). In cachexia, the use of glutamine as a substrate by immune cells is greatly increased, dropping plasma levels. This is compounded by an increase in tumor and splanchnic tissue update and a decrease in skeletal muscle synthesis (Jonker et al. 2012).

Some studies have demonstrated that supplementation with glutamine may improve nutritional parameters and morbidity around surgery and chemotherapy.. For example, in a 2 day crossover trial (Biolo G. et al. 2006) of 6 patients with colorectal and cervical cancer, 2 leg muscle metabolic studies were conducted within the first 48 hours of radical resection with intraoperative radiation therapy comparing an infusion of balanced amino acid with a BCAA- 
enriched solutions (leucine/TAA(g) of 0.09 and 0.22, respectively). Biolo G. et al. (2006) found that although the balanced amino acid solution did not affect outcomes, the BCAA-enriched solution accelerated muscle protein turnover by increasing protein and de novo glutamine synthesis. In a review of the effects of glutamine supplementation on chemotherapy toxicity, Kuhn et al. (2010) found that only $1 / 3$ of the studies using oral and $1 / 2$ of those using parenteral glutamine reported a clinical benefit.

\section{Arginine and citrulline}

Arginine is a semi-EAA with required for adequate nitric oxide synthesis (Figure 1) and necessary for immune function, cell regeneration, tissue perfusion and wound healing. It has a direct and possible indirect stimulation of muscle protein synthesis through its regulation of the mTOR pathway and its role as an insulin secretagogue. In cachexia the metabolism of arginine is altered making it an EAA. Arginine has improved immunological status and survival in surgical, malnourished head and neck cancer (Buijs et al. 2010). Similar to, but more potent in its muscle protein synthesis stimulatory effects than arginine, is citrulline. It is suggested that the effectiveness of citrulline over arginine is due to its superior absorption from the gut and the fact that it avoids hepatic uptakes. However, its effectiveness has only been demonstrated in healthy individuals and is yet to be investigated in patients with cancer.

\section{Creatine}

Creatine is a NEAA popular in research into athletes due to its role in rapid energy provision to skeletal muscle. There have been two recent studies in cancer. In a 6 week pediatric study, Bourgeois et al. (2008) investigated the effects of creatine on attenuating the 
effects of glucocorticosteroids on skeletal muscle during chemotherapy. Nine children with acute lymphocytic leukemia were supplemented with $0.1 \mathrm{~g} / \mathrm{kg}$ body weight/day for 32 weeks. Over the course of the study, supplementation had no effect on BMI, weight or fat-free mass, but did appear to attenuate gains in fat mass (Bourgeois et al. 2008). However, this study was highly heterogeneous with large variance of age, disease stage and corticosteroid use. In a larger, well controlled double blind randomized controlled trial, Norman K. et al. (2006) investigated the effects of creatine supplementation vs placebo as a coadjuvant treatment in colorectal cancer over 8 weeks. In this study, supplementation had a positive effect in HGS, but not muscle function, body cell mass, nutritional parameters or quality of life.

\section{Conclusion}

Alterations in amino kinetics in patients with cancer lead to increased demands for protein and amino acids and to muscle wasting, sarcopenia and cachexia, which are all related to poor outcomes. This paper reviews human studies on amino acid kinetics and the response to nutrition in patients with cancer. These patients have a higher rate of whole body protein turnover and alterations in plasma amino acids. The most recent evidence-based guidelines for patients with cancer recommend a dietary protein intake of 1.0-1.5 g/kg body weight per day. There are promising results from supplementing EAAs or BCAAs on muscle protein synthesis. More research is needed into the optimal amount and quality of protein intake in patients with cancer, and how to target to different cohorts of patients with cancer, such as treatments or stages. 


\section{Research gaps}

Although there has been a lot of research done in healthy adults and older adults, in cancer there is a need for well-designed studies in homogenous groups of patients with cancer, investigating protein requirements and the effects of amino acids or proteins on muscle buildup and clinical outcomes. These are only a few examples for research questions to be addressed in the future:

- What is the optimal dose, duration, frequency and route of administration required to stimulate muscle protein synthesis and does this differ between stages, type of cancer, treatment regimen, age groups?

- What are the effects of long-term increased supplies of protein or modified protein quality / amino acid mixtures on muscle mass and clinical outcomes?

- What is the effect of glutamine enriched nutrition on radiation-related skin toxicity, chemotherapy-related neuropathy, and mucositis?

- What is the effect of combining an exercise program with protein supplementation on body composition, quality of life and clinical outcome, in curative as well as in palliative settings? 


\section{Geolocation information}

BM and LT: Brisbane, Queensland, Australia $\left(27.4698^{\circ} \mathrm{S}, 153.0251^{\circ} \mathrm{E}\right)$

ME and NP: College Station, TX, USA $\left(30.6280^{\circ} \mathrm{N}, 96.3344^{\circ} \mathrm{W}\right)$

\section{Acknowledgement(s)}

Not applicable.

\section{Biographical note}

BM: Conjoint Senior Research Dietitian and expert on translational research on nutrition and muscle wasting in cancer and older adults, focusing on effects of nutritional support strategies such as omega-3 polyunsaturated fatty acids, essential amino acids and meal adaptations, on body composition and quality of life.

LT: Accredited Practising Dietitian and PhD student in nutrition in cancer. Focusing on nutrition assessment methods, the nutrition-related consequences of anti-cancer treatments and medical nutrition therapy.

ME: Associate Professor in the Center for Translational Research in Aging \& Longevity on disturbances in protein and amino acid metabolism underlying muscle wasting, and the anabolic effects of clinical nutrition and exercise in the elderly and in chronic wasting diseases (i.e. Chronic Obstructive Pulmonary Disease, Cystic Fibrosis, and cancer). 
ND: Professor in the Center for Translational Research in Aging \& Longevity with research and interests in clinical nutrition and metabolism research in animals and humans. His clinical interest is using nutritional supplements to treat malnutrition in older adults, and during acute and chronic disease states.

\section{Disclosure statement}

$B M, L T, M E$ and ND declare no conflicts of interest.

\section{Funding}

This work was supported by an Australian Government Research Training Program Scholarship.

\section{Notes on contributor(s)}

Not applicable

\section{Nomenclature/Notation}

\section{Notes}

Not applicable 


\section{References}

Allott EH, Hursting SD. 2015. Obesity and cancer: mechanistic insights from transdisciplinary studies. Endocrine-Related Cancer. 22(6):R365-R386.

Arends J, Bachmann P, Baracos V, Barthelemy N, Bertz H, Bozzetti F, Fearon K, Hutterer E, Isenring E, Kaasa S et al. 2017. ESPEN guidelines on nutrition in cancer patients. Clin Nutr. 36(1):11-48.

Argilés JM. 2017. The 2015 ESPEN Sir David Cuthbertson lecture: Inflammation as the driving force of muscle wasting in cancer. Clinical nutrition (Edinburgh, Scotland). 36:798-803.

Argilés JM, Busquets S, Stemmler B, López-Soriano FJ. 2015. Cachexia and sarcopenia: mechanisms and potential targets for intervention. Current opinion in pharmacology. 22:100-106.

August DA, Huhmann MB. 2009. A.S.P.E.N. clinical guidelines: nutrition support therapy during adult anticancer treatment and in hematopoietic cell transplantation. JPEN J Parenter Enteral Nutr. 33(5):472500. eng.

Baldwin C, Spiro A, Ahern R, Emery PW. 2012. Oral nutritional interventions in malnourished patients with cancer: A systematic review and meta-analysis. Journal of the National Cancer Institute. 104(5):371385.

Baracos VE. 2015. Skeletal muscle anabolism in patients with advanced cancer. The Lancet Oncology. 16:13-14.

Berk L, James J, Schwartz A, Hug E, Mahadevan A, Samuels M, Kachnic L. 2008. A randomized, doubleblind, placebo-controlled trial of a beta-hydroxyl beta-methyl butyrate, glutamine, and arginine mixture for the treatment of cancer cachexia (RTOG 0122). Support Care Cancer. 16(10):1179-1188. eng.

Biolo G, Cederholm T, Muscaritoli M. 2014. Muscle contractile and metabolic dysfunction is a common feature of sarcopenia of aging and chronic diseases: from sarcopenic obesity to cachexia. Clinical nutrition (Edinburgh, Scotland). 33:737-748.

Biolo G, De Cicco M, Dal Mas V, Lorenzon S, Antonione R, Ciocchi B, Barazzoni R, Zanetti M, Dore F, Guarnieri G. 2006. Response of muscle protein and glutamine kinetics to branched-chain-enriched amino acids in intensive care patients after radical cancer surgery. Nutrition. 22(5):475-482. 
Bolasco P, Caria S, Cupisti A, Secci R, Saverio Dioguardi F. 2011. A novel amino acids oral supplementation in hemodialysis patients: a pilot study. Renal failure. 33(1):1-5. eng.

Bosaeus I, Daneryd P, Lundholm K. 2002. Dietary intake, resting energy expenditure, weight loss and survival in cancer patients. The Journal of nutrition. 132(11 Suppl):3465s-3466s. eng.

Bourgeois JM, Nagel K, Pearce E, Wright M, Barr RD, Tarnopolsky MA. 2008. Creatine monohydrate attenuates body fat accumulation in children with acute lymphoblastic leukemia during maintenance chemotherapy. Pediatric blood \& cancer. 51(2):183-187. eng.

Bozzetti F. 2013. Nutritional status, cachexia and survival in patients with advanced colorectal carcinoma. Different assessment criteria for nutritional status provide unequal results. Clin Nutr. 32(5):876. eng.

Brook MS, Wilkinson DJ, Atherton PJ. 2017. Nutrient modulation in the management of disease-induced muscle wasting: evidence from human studies. Curr Opin Clin Nutr Metab Care. 20(6):433-439.

Buijs N, van Bokhorst-de van der Schueren MA, Langius JA, Leemans CR, Kuik DJ, Vermeulen MA, van Leeuwen PA. 2010. Perioperative arginine-supplemented nutrition in malnourished patients with head and neck cancer improves long-term survival. The American journal of clinical nutrition. 92(5):11511156. eng.

Carmichael MJ, Clague MB, Keir MJ, Johnston ID. 1980. Whole body protein turnover, synthesis and breakdown in patients with colorectal carcinoma. The British journal of surgery. 67(10):736-739. eng.

Carneiro IP, Mazurak VC, Prado CM. 2016. Clinical Implications of Sarcopenic Obesity in Cancer. Current Oncology Reports. 18.

Cederholm T, Barazzoni R, Austin P, Ballmer P, Biolo G, Bischoff SC, Compher C, Correia I, Higashiguchi T, Holst $\mathrm{M}$ et al. 2017. ESPEN guidelines on definitions and terminology of clinical nutrition. Clinical Nutrition. 36:49-64.

Choudry HA, Pan M, Karinch AM, Souba WW. 2006. Branched-chain amino acid-enriched nutritional support in surgical and cancer patients. The Journal of nutrition. 136(1 Suppl):314s-318s. eng. 
Coa KI, Epstein JB, Ettinger D, Jatoi A, McManus K, Platek ME, Price W, Stewart M, Teknos TN, Moskowitz B. 2015. The impact of cancer treatment on the diets and food preferences of patients receiving outpatient treatment. Nutrition and Cancer. 67:339-353.

Cruz-Jentoft AJ, Baeyens JP, Bauer JM, Boirie Y, Cederholm T, Landi F, Martin FC, Michel JP, Rolland Y, Schneider SM et al. 2010. Sarcopenia: European consensus on definition and diagnosis: Report of the European Working Group on Sarcopenia in Older People. Age and ageing. 39(4):412-423. eng.

de Blaauw I, Heeneman S, Deutz NE, von Meyenfeldt MF. 1997. Increased whole-body protein and glutamine turnover in advanced cancer is not matched by an increased muscle protein and glutamine turnover. The Journal of surgical research. 68(1):44-55. eng.

Deans DA, Tan BH, Wigmore S, Ross J, de Beaux AC, Paterson-Brown S, Fearon KC. 2009. The influence of systemic inflammation, dietary intake and stage of disease on rate of weight loss in patients with gastrooesophageal cancer. Br J Cancer. 100:63-69.

Deutz NE, Safar A, Schutzler S, Memelink R, Ferrando A, Spencer H, van Helvoort A, Wolfe RR. 2011. Muscle protein synthesis in cancer patients can be stimulated with a specially formulated medical food. Clin Nutr. 30(6):759-768.

Deutz NE, Simbo SY, Ligthart-Melis GC, Cynober L, Smriga M, Engelen MP. 2017. Tolerance to increased supplemented dietary intakes of methionine in healthy older adults. The American journal of clinical nutrition. 106(2):675-683. eng.

DeWys WD, Begg C, Band P, Tormey D. 1981. The impact of malnutrition on treatment results in breast cancer. Cancer treatment reports. 65 Suppl 5:87-91. eng.

Dioguardi FS. 2011. Clinical use of amino acids as dietary supplement : pros and cons. Review Literature And Arts Of The Americas.75-80.

Dworzak F, Ferrari P, Gavazzi C, Maiorana C, Bozzetti F. 1998. Effects of cachexia due to cancer on whole body and skeletal muscle protein turnover. Cancer. 82(1):42-48. eng.

Emery PW, Edwards RH, Rennie MJ, Souhami RL, Halliday D. 1984. Protein synthesis in muscle measured in vivo in cachectic patients with cancer. British medical journal (Clinical research ed). 289(6445):584586. eng. 
Engelen M, Deutz NEP. 2018. Is beta-hydroxy beta-methylbutyrate an effective anabolic agent to improve outcome in older diseased populations? Curr Opin Clin Nutr Metab Care. eng.

Engelen MP, Safar AM, Bartter T, Koeman F, Deutz NE. 2016. Reduced arginine availability and nitric oxide synthesis in cancer is related to impaired endogenous arginine synthesis. Clin Sci (Lond). 130:11851195.

Engelen MP, van der Meij BS, Deutz NE. 2016. Protein anabolic resistance in cancer: does it really exist? Curr Opin Clin Nutr Metab Care. 19(1):39-47.

Engelen MPKJ, van der Meij BS, Deutz NEP. 2016. Protein anabolic resistance in cancer: Does it really exist? Current Opinion in Clinical Nutrition and Metabolic Care. 19:39-47.

Fearon K, Strasser F, Anker SD, Bosaeus I, Bruera E, Fainsinger RL, Jatoi A, Loprinzi C, MacDonald N, Mantovani G et al. 2011. Definition and classification of cancer cachexia: an international consensus. The Lancet Oncology. 12(5):489-495. eng.

Fearon KC, Hansell DT, Preston T, Plumb JA, Davies J, Shapiro D, Shenkin A, Calman KC, Burns HJ. 1988. Influence of whole body protein turnover rate on resting energy expenditure in patients with cancer. Cancer research. 48(9):2590-2595. eng.

Fukutake N, Ueno M, Hiraoka N, Shimada K, Shiraishi K, Saruki N, Ito T, Yamakado M, Ono N, Imaizumi A et al. 2015. A Novel Multivariate Index for Pancreatic Cancer Detection Based On the Plasma Free Amino Acid Profile. PLoS One. 10(7):e0132223. eng.

Geisler C, Prado CM, Muller MJ. 2016. Inadequacy of Body Weight-Based Recommendations for Individual Protein Intake-Lessons from Body Composition Analysis. Nutrients. 9(1).

Gilliam LAA, St Clair DK. 2011. Chemotherapy-induced weakness and fatigue in skeletal muscle: the role of oxidative stress. Antioxidants \& redox signaling. 15:2543-2563.

Gioulbasanis I, Martin L, Baracos VE, Thézénas S, Koinis F, Senesse P. 2015. Nutritional assessment in overweight and obese patients with metastatic cancer: does it make sense? Annals of Oncology. 26:217221. 
Gould DW, Lahart I, Carmichael AR, Koutedakis Y, Metsios GS. 2013. Cancer cachexia prevention via physical exercise: Molecular mechanisms. Journal of Cachexia, Sarcopenia and Muscle. 4:111-124.

Guadagni M, Biolo G. 2009. Effects of inflammation and/or inactivity on the need for dietary protein. Curr Opin Clin Nutr Metab Care. 12(6):617-622. eng.

Härter J, Orlandi SP, Gonzalez MC. 2017. Nutritional and functional factors as prognostic of surgical cancer patients. Supportive care in cancer : official journal of the Multinational Association of Supportive Care in Cancer.

Hébuterne X, Lemarié E, Michallet M, de Montreuil CB, Schneider SM, Goldwasser F. 2014. Prevalence of malnutrition and current use of nutrition support in patients with cancer. JPEN Journal of parenteral and enteral nutrition. 38:196-204.

Hopanci Bicakli D, Ozkaya Akagunduz O, Meseri Dalak R, Esassolak M, Uslu R, Uyar M. 2017. The Effects of Compliance with Nutritional Counselling on Body Composition Parameters in Head and Neck Cancer Patients under Radiotherapy. Journal of nutrition and metabolism. 2017:8631945. eng.

Hung Y-C, Bauer J, Horsley P, Waterhouse M, Bashford J, Isenring E. 2013. Changes in nutritional status, body composition, quality of life, and physical activity levels of cancer patients undergoing autologous peripheral blood stem cell transplantation. Supportive care in cancer : official journal of the Multinational Association of Supportive Care in Cancer. 21:1579-1586.

Ihata Y, Miyagi E, Numazaki R, Muramatsu T, Imaizumi A, Yamamoto H, Yamakado M, Okamoto N, Hirahara F. 2014. Amino acid profile index for early detection of endometrial cancer: verification as a novel diagnostic marker. International Journal of Clinical Oncology. 19:364-372.

Jeevanandam M, Horowitz GD, Lowry SF, Brennan MF. 1984. Cancer cachexia and protein metabolism. Lancet (London, England). 1(8392):1423-1426. eng.

Jonker R, Engelen MPKJ, Deutz NEP. 2012. Role of specific dietary amino acids in clinical conditions. British Journal of Nutrition. 108:S139-S148.

Keum N, Greenwood DC, Lee DH, Kim R, Aune D, Ju W, Hu FB, Giovannucci EL. 2015. Adult Weight Gain and Adiposity-Related Cancers: A Dose-Response Meta-Analysis of Prospective Observational Studies. $\mathrm{JNCl}$ : Journal of the National Cancer Institute. 107. 
Khalid U, Spiro a, Baldwin C, Sharma B, McGough C, Norman aR, Eisen T, O'Brien MER, Cunningham D, Andreyev HJN. 2007. Symptoms and weight loss in patients with gastrointestinal and lung cancer at presentation. Supportive care in cancer : official journal of the Multinational Association of Supportive Care in Cancer. 15:39-46.

Kitagawa M, Haji S, Amagai T. 2017. High Serum Essential Amino Acids as a Predictor of Skeletal Muscle Depletion in Patients With Cachexia and Advanced Gastrointestinal Cancers. Nutrition in Clinical Practice. 32:645-651.

Kuhn KS, Muscaritoli M, Wischmeyer P, Stehle P. 2010. Glutamine as indispensable nutrient in oncology: experimental and clinical evidence. European journal of nutrition. 49(4):197-210. eng.

Lai H-S, Lee J-C, Lee P-H, Wang S-T, Chen W-J. 2005. Plasma free amino acid profile in cancer patients. Seminars in cancer biology. 15:267-276.

Leguina-Ruzzi A, Cariqueo M. 2017. Glutamine: A Conditionally Essential Amino Acid with Multiple Biological Functions. In: Shiomi N, Waisundara V, editors. Superfood and Functional Food - The Development of Superfoods and Their Roles as Medicine. Rijeka: InTech; p. Ch. 10.

Lua PL, Salihah NZ, Mazlan N. 2012. Nutritional status and health-related quality of life of breast cancer patients on chemotherapy. Malaysian journal of nutrition. 18(2):173-184. eng.

Ma H, Hasim A, Mamtimin B, Kong B, Zhang HP, Sheyhidin I. 2014. Plasma free amino acid profiling of esophageal cancer using high-performance liquid chromatography spectroscopy. World journal of gastroenterology. 20(26):8653-8659. eng.

MacDonald AJ, Johns N, Stephens N, Greig C, Ross JA, Small AC, Husi H, Fearon KC, Preston T. 2015. Habitual Myofibrillar Protein Synthesis Is Normal in Patients with Upper GI Cancer Cachexia. Clin Cancer Res. 21(7):1734-1740.

Madeddu C, Macciò A, Astara G, Massa E, Dessì M, Antoni G, Panzone F, Serpe R, Mantovani G. 2010. Open phase II study on efficacy and safety of an oral amino acid functional cluster supplementation in cancer cachexia. Mediterranean Journal of Nutrition and Metabolism. 3(2):165-172.

Marinangeli CPF, House JD. 2017. Potential impact of the digestible indispensable amino acid score as a measure of protein quality on dietary regulations and health. Nutrition Reviews. 75:658-667. 
Martin L, Birdsell L, Macdonald N, Reiman T, Clandinin MT, McCargar LJ, Murphy R, Ghosh S, Sawyer MB, Baracos VE. 2013. Cancer cachexia in the age of obesity: skeletal muscle depletion is a powerful prognostic factor, independent of body mass index. Journal of clinical oncology : official journal of the American Society of Clinical Oncology. 31:1539-1547.

Martin L, Senesse P, Gioulbasanis I, Antoun S, Bozzetti F, Deans C, Strasser F, Thoresen L, Jagoe RT, Chasen M et al. 2014. Diagnostic Criteria for the Classification of Cancer-Associated Weight Loss. Journal of clinical oncology : official journal of the American Society of Clinical Oncology.

May PE, Barber A, D'Olimpio JT, Hourihane A, Abumrad NN. 2002. Reversal of cancer-related wasting using oral supplementation with a combination of beta-hydroxy-beta-methylbutyrate, arginine, and glutamine. American journal of surgery. 183(4):471-479. eng.

Midgley AW, Lowe D, Levy AR, Mepani V, Rogers SN. 2017. Exercise program design considerations for head and neck cancer survivors. European Archives of Oto-Rhino-Laryngology. 275(1):1-11.

Miyagi Y, Higashiyama M, Gochi A, Akaike M, Ishikawa T, Miura T, Saruki N, Bando E, Kimura H, Imamura F et al. 2011. Plasma free amino acid profiling of five types of cancer patients and its application for early detection. PLOS ONE. 6.

Moses AWG, Slater C, Preston T, Barber MD, Fearon KCH. 2004. Reduced total energy expenditure and physical activity in cachectic patients with pancreatic cancer can be modulated by an energy and protein dense oral supplement enriched with n-3 fatty acids. British Journal of Cancer. 90:996-1002.

Naito T, Okayama T, Aoyama T, Ohashi T, Masuda Y, Kimura M, Shiozaki H, Murakami H, Kenmotsu H, Taira T et al. 2017. Skeletal muscle depletion during chemotherapy has a large impact on physical function in elderly Japanese patients with advanced non-small-cell lung cancer. BMC Cancer. 17:571.

Nicastro H, da Luz CR, Chaves DF, Bechara LR, Voltarelli VA, Rogero MM, Lancha AH, Jr. 2012. Does Branched-Chain Amino Acids Supplementation Modulate Skeletal Muscle Remodeling through Inflammation Modulation? Possible Mechanisms of Action. Journal of nutrition and metabolism. 2012:136937. 
Norman K, Stobäus N, Smoliner C, Zocher D, Scheufele R, Valentini L, Lochs H, Pirlich M. 2010.

Determinants of hand grip strength, knee extension strength and functional status in cancer patients. Clinical Nutrition. 29:586-591.

Norman K, Stubler D, Baier P, Schutz T, Ocran K, Holm E, Lochs H, Pirlich M. 2006. Effects of creatine supplementation on nutritional status, muscle function and quality of life in patients with colorectal cancer--a double blind randomised controlled trial. Clin Nutr. 25(4):596-605.

Owusu C, Margevicius S, Schluchter M, Koroukian SM, Berger NA. 2017. Short Physical Performance Battery, usual gait speed, grip strength and Vulnerable Elders Survey each predict functional decline among older women with breast cancer. Journal of Geriatric Oncology. 8:356-362.

Pamoukdjian F, Bouillet T, Lévy V, Soussan M, Zelek L, Paillaud E. 2017. Prevalence and predictive value of pre-therapeutic sarcopenia in cancer patients: A systematic review. Clinical Nutrition.

Perriello G, Nurjhan N, Stumvoll M, Bucci A, Welle S, Dailey G, Bier DM, Toft I, Jenssen TG, Gerich JE. 1997. Regulation of gluconeogenesis by glutamine in normal postabsorptive humans. Am J Physiol. 272:E437-445.

Peters SJ, van Helvoort A, Kegler D, Argiles JM, Luiking YC, Laviano A, van Bergenhenegouwen J, Deutz NE, Haagsman HP, Gorselink M et al. 2011. Dose-dependent effects of leucine supplementation on preservation of muscle mass in cancer cachectic mice. Oncology reports. 26(1):247-254. eng.

Pistoia LF, de Abreu Nunes CH, Andreatta Gottschall B, Rabito El. 2012. Dietary intake of cancer patients on radiotherapy. Nutricion hospitalaria. 27(6):1936-1939. eng.

Prado CM, Sawyer MB, Ghosh S, Lieffers JR, Esfandiari N, Antoun S, Baracos VE. 2013. Central tenet of cancer cachexia therapy: do patients with advanced cancer have exploitable anabolic potential? The American journal of clinical nutrition. 98(4):1012-1019.

Proenza AM, Oliver J, Palou A, Roca P. 2003. Breast and lung cancer are associated with a decrease in blood cell amino acid content. The Journal of nutritional biochemistry. 14:133-138.

Ravasco P, Monteiro-Grillo I, Marques Vidal P, Camilo ME. 2005. Impact of nutrition on outcome: a prospective randomized controlled trial in patients with head and neck cancer undergoing radiotherapy. Head \& neck. 27(8):659-668. eng. 
Rock CL, Doyle C, Demark-Wahnefried W, Meyerhardt J, Courneya KS, Schwartz AL, Bandera EV, Hamilton KK, Grant B, McCullough M et al. 2012. Nutrition and physical activity guidelines for cancer survivors. CA: a cancer journal for clinicians. 62(4):243-274. eng.

Romero SAD, Li QS, Mao JJ. 2017. Factors and barriers associated with changes in physical activity after cancer diagnosis. Journal of Clinical Oncology. 35(5_suppl):162-162.

Rutten IJG, Ubachs J, Kruitwagen RFPM, van Dijk DPJ, Beets-Tan RGH, Massuger LFAG, Olde Damink SWM, Van Gorp T. 2017. The influence of sarcopenia on survival and surgical complications in ovarian cancer patients undergoing primary debulking surgery. European Journal of Surgical Oncology (EJSO). 43:717-724.

Sánchez-Lara K, Sosa-Sánchez R, Green-Renner D, Rodríguez C, Laviano A, Motola-Kuba D, Arrieta O. 2010. Influence of taste disorders on dietary behaviors in cancer patients under chemotherapy. Nutrition Journal. 9:15-15.

Schmitz KH, Courneya KS, Matthews C, Demark-Wahnefried W, Galvão DA, Pinto BM, Irwin ML, Wolin KY, Segal RJ, Lucia A et al. 2010. American college of sports medicine roundtable on exercise guidelines for cancer survivors. Medicine and Science in Sports and Exercise. 42(7):1409-1426.

Segal R, Zwaal C, Green E, Tomasone JR, Loblaw A, Petrella T, Group Exercise for People with Cancer Guideline Development. 2017. Exercise for people with cancer: a systematic review. Current oncology. 24:e290-e315.

Shachar SS, Williams GR, Muss HB, Nishijima TF. 2016. Prognostic value of sarcopenia in adults with solid tumours: A meta-analysis and systematic review. European Journal of Cancer. 57:58-67.

Shen J, Yan L, Liu S, Ambrosone CB, Zhao H. 2013. Plasma metabolomic profiles in breast cancer patients and healthy controls: by race and tumor receptor subtypes. Translational oncology. 6:757-765.

Silva de Paula N, de Aguiar Bruno K, Azevedo Aredes M, Villaca Chaves G. 2018. Sarcopenia and Skeletal Muscle Quality as Predictors of Postoperative Complication and Early Mortality in Gynecologic Cancer. Int J Gynecol Cancer. 28(2):412-420. eng. 
Sjøblom B, Grønberg BH, Wentzel-Larsen T, Baracos VE, Hjermstad MJ, Aass N, Bremnes RM, Fløtten $\varnothing$, Bye A, Jordh øy M. 2016. Skeletal muscle radiodensity is prognostic for survival in patients with advanced non-small cell lung cancer. Clinical nutrition (Edinburgh, Scotland). 35:1386-1393.

Solerte SB, Gazzaruso C, Bonacasa R, Rondanelli M, Zamboni M, Basso C, Locatelli E, Schifino N, Giustina A, Fioravanti M. 2008. Nutritional supplements with oral amino acid mixtures increases whole-body lean mass and insulin sensitivity in elderly subjects with sarcopenia. The American journal of cardiology. 101(11a):69e-77e. eng.

Stobaus N, Muller MJ, Kupferling S, Schulzke JD, Norman K. 2015. Low Recent Protein Intake Predicts Cancer-Related Fatigue and Increased Mortality in Patients with Advanced Tumor Disease Undergoing Chemotherapy. Nutr Cancer. 67(5):818-824.

Tanaka S, Imataki O, Kitaoka A, Fujioka S, Hanabusa E, Ohbayashi Y, Uemura M, Arima N, Yamamoto T. 2017. Clinical impact of sarcopenia and relevance of nutritional intake in patients before and after allogeneic hematopoietic stem cell transplantation. Journal of Cancer Research and Clinical Oncology. 143:1083-1092.

Teodozio CGC, Chaves GV, Arcuri IP, Frajacomo FT. 2017. Does grip strength decrease in the very early stages of hematological treatment? Supportive Care in Cancer. 26(2):333-335.

Thraen-Borowski KM, Gennuso KP, Cadmus-Bertram L. 2017. Accelerometer-derived physical activity and sedentary time by cancer type in the United States. PLoS ONE. 12.

Tipton KD, Gurkin BE, Matin S, Wolfe RR. 1999. Nonessential amino acids are not necessary to stimulate net muscle protein synthesis in healthy volunteers. J Nutr Biochem. 10(2):89-95. eng.

Trabal J, Leyes P, Forga MT, Hervas S. 2006. Quality of life, dietary intake and nutritional status assessment in hospital admitted cancer patients. Nutricion hospitalaria. 21(4):505-510. eng.

Turkoglu O, Zeb A, Graham S, Szyperski T, Szender JB, Odunsi K, Bahado-Singh R. 2016. Metabolomics of biomarker discovery in ovarian cancer: a systematic review of the current literature. Metabolomics. 12.

Uster A, Ruefenacht U, Ruehlin M, Pless M, Siano M, Haefner M, Imoberdorf R, Ballmer PE. 2013. Influence of a nutritional intervention on dietary intake and quality of life in cancer patients: A randomized controlled trial. Nutrition. 29:1342-1349. 
van den Berg MMGA, Winkels RM, de Kruif JTCM, van Laarhoven HWM, Visser M, de Vries JHM, de Vries YC, Kampman E. 2017. Weight change during chemotherapy in breast cancer patients: a meta-analysis. BMC Cancer. 17:259.

van Dijk DP, van de Poll MC, Moses AG, Preston T, Olde Damink SW, Rensen SS, Deutz NE, Soeters PB, Ross JA, Fearon $\mathrm{K}$ et al. 2015. Effects of oral meal feeding on whole body protein breakdown and protein synthesis in cachectic pancreatic cancer patients. J Cachexia Sarcopenia Muscle. 6(3):212-221.

Vermaete N, Wolter P, Verhoef G, Gosselink R. 2014. Physical activity and physical fitness in lymphoma patients before, during, and after chemotherapy: a prospective longitudinal study. Annals of hematology. 93:411-424.

Vissers YLJ, Dejong CHC, Luiking YC, Fearon KCH, von Meyenfeldt MF, Deutz NEP. 2005. Plasma arginine concentrations are reduced in cancer patients: evidence for arginine deficiency? The American journal of clinical nutrition. 81:1142-1146.

Ward C. 2015. Amino acid metabolism. Internet: Diapedia 5105758814 rev. no. 45; [updated 18 November 2015; accessed 201828 February 2018]. https://doi.org/10.14496/dia.5105758814.45.

Williams JP, Phillips BE, Smith K, Atherton PJ, Rankin D, Selby AL, Liptrot S, Lund J, Larvin M, Rennie MJ. 2012. Effect of tumor burden and subsequent surgical resection on skeletal muscle mass and protein turnover in colorectal cancer patients. The American journal of clinical nutrition. 96(5):1064-1070.

Winter A, MacAdams J, Chevalier S. 2012. Normal protein anabolic response to hyperaminoacidemia in insulin-resistant patients with lung cancer cachexia. Clin Nutr. 31(5):765-773.

Wolfe RR. 2002. Regulation of muscle protein by amino acids. The Journal of nutrition. 132(10):3219s3224s. eng.

Wu G. 2009. Amino acids: Metabolism, functions, and nutrition. Amino Acids. 37(1):1-17.

Young VR, Bier DM. 1987. Amino acid requirements in the adult human: how well do we know them? The Journal of nutrition. 117(8):1484-1487. eng. 


\section{Figure captions}

Figure 1. Interaction of the TCA cycle, Nitric Oxide cycle and Urea cycle [adapted from: Ward (2015)]

Figure 2. Methionine homocysteine cycle [adapted from Ward (2015)]

Figure 3. Muscle metabolism of branched chain amino acids (BCAAs), glutamine and alanine [adapted from Leguina-Ruzzi and Cariqueo (2017)]

\section{Table captions}

Table 1. Summary of disturbances in plasma amino acid levels in patients with cancer compared to healthy controls

Table 2. Digestible indispensable amino acid score (DIAAS) for common proteinrich foods [adapted from Marinangeli and House (2017)] 